\title{
Embracing the Challenges and Opportunities of Change Through Electronic Collaboration
}

Cathrine Linnes, Østfold University College, Norway

\begin{abstract}
Globalization is a key reason why an organization outsources its activities or creates virtual teams to remain competitive in today's international market. Organizations are utilizing new technologies to become more efficient and employees frequently collaborate by using e-tools at work. Today's workers are faced with a fast-paced work environment with frequently changing requirements and digital innovations. Keeping up with the development can be a challenge. Incorporating e-collaboration into the student learning process is, therefore, crucial to the modern learning environment as it prepares students to work in teams. This has become even more important now after the COVID-19. The pandemic has forced universities to go online at a record speed and the workforce to work from home. This study looks at the e-collaboration success, challenges, perception, and tools and delves into a quantitative study of graduate students who have been working on semester-long corporate projects in the information systems discipline.
\end{abstract}

\section{KEYWORDS}

Collaborative Work, E-Collaboration, Project-Based Learning, Remote Teams, Team Effectiveness, Virtual Teams

\section{INTRODUCTION}

It is no surprise that an organization's culture and value direct the way its employees perform, behave, and adapt at work. People and culture lie at the heart of organizational performance and typically drive both success and failure. This means that culture ultimately determines how and to what extent employees handle the digital workplace to connect, communicate and collaborate. The secret is to recognize how employees prefer to work and guide them in the 
change process. We presently have Generations X, Y, Z and Baby Boomers in the workforce; the Baby Boomers will soon faze out and Generation $\mathrm{Z}$ is taking over. However, in the meantime, people have grown up in different times and their skill level and comfort with technology differs. It is, therefore, important that organizations develop a digital plan that aligns with their corporate culture. By adapting this cultural change and unifying their technology components, the digital workplace can help to improve the organization's collaboration and communication process. There is no doubt that traditional co-located work teams have been challenged by the urgent need for the team to operate $24 / 7$ and be able to make rapid modifications without losing productivity if team members change. Organizations have been investing in their virtual teams to increase company performance and ensure that the company remain competitive (Linnes, 2016). People are connected by cell phones, tablets, and computers by using the internet, social media and video conferencing technologies such as ZOOM, Teams and Webex. Today 59\% of the world's population is connected to the Internet; this figure is up from $46.1 \%$ in 2016 (Statista, 2020). Statistics show that internet usage has demonstrated a steady increase during the last 18 years. In North America, $88.1 \%$ of the population is connected to the internet, with the world average at $51 \%$, which makes it possible to collaborate at a distance (Internet World Stats, 2020).

Several studies have been conducted on e-collaboration which set the stage for this study. Tseng et.al. (2009) carried out a study on 46 graduate students to better understand the experience of student teamwork by looking at the relationship between the factors of coordination and satisfaction with teamwork. Karna and Ko (2013) explore the impact of e-collaboration on research performance, reward, and satisfaction. Razmerita \& Kirchner (2019) studied MOOCs on how virtual environments fail to provide social interaction on knowledge exchanges between the online students. Oertig and Buergi (2006) looks at the challenges presented by project leaders of virtual project teams in ABC, a multinational company based in Switzerland. Graham \& Miaoulis (2013) looked at student collaboration using SMS text to see if the technology improved student understanding of the information presented, relating it to the Myer-Briggs Personality Type Indicator. Razmerita \& Kirchner (2015) looks at how students perceive collaboration and how these students use new technologies and which factors influence their performance. Graham, Daniel \& Doore (2020) recently focused on millennial students assigned to virtual teams charged with creating a database management system within a virtual environment.

Therefore, the purpose of this research is to investigate the success and challenges of e-collaboration among college students working on semester-long project-based learning assignments. Specifically, the following questions are attempted to be answered: a) What are the factors that influence the team collaboration environment? and b) Does the usage of e-collaboration tools influence project success? 


\section{BACKGROUND}

Electronic collaboration (e-collaboration) is defined as teamwork that is facilitated by the use of electronic technologies such as video conferencing, text messaging, version control repository, e-mail, Google Docs, etc., for a group to accomplish a common task (Kock, Davidson, Ocker, \& Wazlawick, 2001; Kock \& D’Arcy, 2002; Knock, 2008). This is a broad definition, but it captures the essence of virtual teams.

Further, virtual partnerships such as these are referred to as geographically dispersed teams (GDTs). These GDTs consist of employees who work across time zones, locations, and organizational boundaries with links strengthened by webs of communication technology. Team members have complementary skills and are committed to a common purpose, have interdependent performance goals, and share an approach to work for which they hold themselves mutually accountable. GDTs allow organizations to hire and retain the best individuals without regard for location. A virtual team does not always mean teleworkers. Teleworkers are defined as individuals who work from home at the same time, and smart work means having the possibility to carry out the work without having to be tied to the workplace at specific times. Many virtual teams in today's organizations consist of employees both working at home and in small groups in the office, but in different geographic locations. According to Greg Ciotti (2016), virtual teams still constitute an ongoing experiment, as this way of working has only been fully incorporated by organizations the last decade. The president of Global Workplace Analytics Kate Lister (2020) estimated that 25-30\% of the workforce to be working from home several days a week by the end of 2021 .

It has become more common for organizations to rely on virtual teams to accomplish business tasks (Heller et al., 2010; Martins et al., 2004; Zivick, 2012; Linnes, 2016). According to Knuppel (2015), virtual teams are becoming more popular and growing faster than managers can adapt and lead with efficiency. According to Dixon (2019) $61 \%$ of organizations worldwide have a remote working policy of some sort. One can even read that flexible working has become the new norm (Hering, 2020; Zapier, 2020). SHRM (2019) stated that the departments most likely to use virtual teams are HR $(63 \%)$, sales $(62 \%)$, IT $(57 \%)$ operations $(57 \%)$, and finance $(56 \%)$. Worldwide, $63 \%$ of all departments in an organization have employees who work remotely (Inavero Inc., 2018). It is also found that $53 \%$ of organizations are embracing more flexible teams compared to three years ago (Inavero Inc., 2018). Further, a survey of 1000 workers conducted by uSamp indicated that $69 \%$ of large organizations offer their employees telecommuting flexibilities (Parris, 2013). However, 23\% of the surveyed participants indicated that they opted to work from the office to engage in face-toface interactions and $47 \%$ chose to do so because it was expected of them (Parris, 2013). According to a study conducted by PricewaterhouseCoopers (2013), 44,000 Millennial participants indicated that they want greater work flexibility. In 2014, a study was conducted on 1,5000 FlexJobs users (a leading job search site specializing in remote, part-time, freelance, and flexible jobs available) in which $79 \%$ of the users 
preferred finding a job that offered telecommuting. The main reasons that were cited included work-life balance, family reasons, health and exercise, reduced commute and cost savings (Reynolds, 2014). According to Jones (2015), the average telecommuter commutes two days per month. In Canada alone, 1.7 million employees worked from home at least once a week in 2016, not including self-employed people (Marrowits, 2016). Another study reported that $54 \%$ of professionals prefer to work from home (Reynolds, 2014) and 50\% of U.S. workers hold a job that is compatible with working from home (Global Workplace Analytics, 2015b). Data for 2018 indicate that $70 \%$ of the global workforce works remotely at least once a week (Browne, 2018).

\section{Corporate Trends}

Yahoo has taken steps to ban telecommuting to increase interaction between coworkers (CBC News, 2013). This is perhaps not the wisest move this company has made, as there are many degrees of telecommuting; one does not need to be all in or out. A week later, Yahoo announced that it would bring its employees back to the office, and Best Buy announced that it would end its flexible work policy as well (Tkaczyk, 2013). Bank of America is another organization who chose to scale back its 10-yearold telecommuting program. The reason for the change was to provide opportunities for in-person collaboration and bring employees together in the same physical space to better serve the customers and clients (Roberts, 2014). Further, Honeywell announced a new policy that only allows work from home to be approved from the top, upsetting several workers who had relied on this privilege (DePass, 2016). Even IBM announced that it would be cracking down on its work-from-home program (Mosca, 2017). On the other hand, Virgin Atlantic's Richard Branson pointed out that one day offices will be a thing from the past (Ciotti, 2016). Mr. Branson was correct. The debate has certainly started-deliberating whether or not virtual teams perform the same as those working from the office.

Despite the prior decisions, AT\&T reported that its telecommuters worked more hours at home than its traditional office workers (Kratz, 2016). JD Edwards reported that its teleworkers were 20-25\% more productive than the traditional worker (Kratz, 2016). American Express asserted that employees who worked from home were $43 \%$ more productive than workers in the office (Kratz, 2016). Statistics also show that it is easier to recruit and retain employees when offering flexibility. In the long run, companies will save on hiring and training costs as telecommuting will most likely lead to happier employees who are more productive and less likely to quit. These folks are also less likely to take sick days (Kratz, 2016). Further, companies can also save on real estate costs. The savings are estimated to be approximately $\$ 10,000$ a year per worker. For example, IBM cut real estate costs by $\$ 50$ million and Sun Microsystems saved $\$ 68$ million a year by moving towards telecommuting (Global Workplace Analytics, 2015a; Kratz, 2016). Under the Telework Enhancement Act of 2010, federal agencies are required to establish policies allowing certain employees to work remotely and report these hours to their Office of Personnel Management 
(OPM) and OPM is required to submit an annual report to Congress (Singletary, 2014). Despite the positive or negative downfalls, telecommuting is not for everyone or every position. However, employers should explore the possibilities.

The Census Bureau's American Community Survey surprisingly reported that the typical telecommuter is a 49-year-old college graduate who earns approximately $\$ 58,000$ annually and who works for a company with 100 or more employees (Tugend, 2014). According to Reynolds (2018), the Flexjobs.com report indicated that industries such as technology, mathematics, military, arts and design, entertainment, sports, media, personal care, and financial services offer the greatest possibility to work remotely. A four-day government shutdown in 2010 was reported to cost the federal government between $\$ 70$ million to $\$ 100$ million (Ballenstedt, 2014). Federal employees in Washington who worked from home during snow days saved the government an estimated $\$ 32$ million (Tugend, 2014). A study by CISCO stated that employees who telecommute save organizations money and also experience higher rates of productivity, work-life flexibility, and overall satisfaction (Schwartz, 2009). CISCO (2009) reported that approximately $69 \%$ of the employees surveyed cited higher productivity when working remotely, and $75 \%$ of those surveyed reported that the timeliness of their work improved. Further, $83 \%$ of the employees said that their ability to communicate and collaborate with coworkers was the same, if not better, than it was when working on-site. With a large majority of employees having similar or enhanced communication with their coworkers despite being physically removed from them, it is safe to say that remote working has the potential to be just as successful as in-office work for many companies; it just requires the team in question to make the needed adjustments. Regardless of what a corporation decided prior, the situation has changed, working remotely is no longer a perk, it has become a mandatory process for millions of workers (Zapier, 2020).

Corporations with successful telecommuting teams are aware that: a) telecommuting is not for every employee, department or organization. Some employees simply do not like working from home while others lack the skills to perform well at home, but there are those workers who thrive; b) telecommuting can mean anything from a few days each month to $100 \%$ at-home work; and c) what works for one department or company will not necessarily work well for another. Therefore, smart employers create programs that work for their own company dynamic, culture and employees.

\section{E-COLLABORATION TEAMS}

There are similarities between traditional teams and virtual teams: One must have a clear purpose; the goals must be measurable; there must be team guidelines, great communication and decision-making skills and the most effective team size is reported to be between 3-12 members. It is also important for virtual teams to have strong leadership (Chen, Wu, Yang \& Tsou, 2008). According to Lipnack and Stamps (1997), a 
shared leadership among the team members is more effective than centralized guidance. In lieu of the global trend, organizations are finding it necessary to use e-collaboration tools and virtual teams in their operation (Jones, 2015). However, the process' success relies on many elements besides the subject knowledge such as culture, leadership, trust, relationship and, of course, the technology that is selected. Communication is the most essential component that enables any work team to remain successful.

As stated by Thompson and Caputo (2009), virtual teams can indeed improve employee productivity; some organizations have even seen gains up to $43 \%$. A more recent report stated that American companies saved up to $\$ 44$ billion ( $\operatorname{Radu}, 2018$ ). Furthermore, Ferrazzi (2012) reported that virtual teams can outperform traditional work teams, as was evident in a study conducted on 80 software development teams. Virtual teams in which employees can work from a distance provide better working conditions, in terms of a better work-life balance for the employee, cost savings for the organization and a reduced footprint for society. The worker can have flexible business hours and enjoy the additional comfort of being able to work from home. It gives workers the freedom to travel as one can work from anywhere in the world, which can lead to happier and more loyal long-term employees. The organizations save money on office space and the turnaround time is improved by the fact that the global workday is 24/7, rather than just 8 hours. Further, the digital work is greener as there is no need for transportation to get to and from work and documents are more commonly shared electronically (Kayworth \& Leidner, 2000). E-collaboration also helps to increase the globalization of trade and corporate activity. There is also a larger and more qualified pool of employees from which to select. This trend has also changed largely in the acquisition, analysis, and handling of information, rather than in the production of goods or services. This concept was brought to the surface and made popular by the U.S. management specialist Peter Drucker (WebFinance, 2017). For an e-collaboration team to be effective, it is important to pay attention to the challenges that may arise, such as the team composition, culture, communication, trust and structural obstacles (Deloitte, 2011; Hamburg, 2019; Morrison-Smith \& Ruiz, 2020; Oertig \& Buergi, 2006; SHRM, 2020; Yusuf, 2012). In addition, having taught project-based learning with students from various nations with different upbringings one can clearly see the importance of these factors for the project to be a success.

\section{Team Composition}

It is vital for a virtual team to have qualified leadership that exhibits competence in working in virtual environments. Team leaders need to set high performance expectations; model behaviors such as working across boundaries and using technology effectively. Marks, Sabella, Burke, and Zaccaro (2002) stated that challenges facing any team include: poor team member composition, a failure to fully understand the project goals, and poor coordination processes. According to the Economist Intelligence Unit (2009) one in three executives agrees that virtual teams are poorly managed. The reason for this is that the virtual teams have been created alongside the development of the technology instead of making it into the strategic plan. Last, it is important 
for there to be different types of skill sets in a group and that the team members feel comfortable using electronic tools to collaborate. If this environment feels foreign, then it becomes almost impossible to succeed. In addition, Brandt, England and Ward (2011) stated that companies must make sure the virtual teams have the ability to assemble quickly and be extremely adaptable to meet the project goals.

\section{Culture}

Several studies have focused on individual differences enabling teams to succeed, such as Ang and Van Dyne, (2008), Johnson et al. (2006), and Shapiro et al. (2008). When team members are raised in different countries, speak different languages, or have different cultural backgrounds and different belief systems, it can be a challenge because everyone works and behaves according to their own upbringing. However, it can all be overcome if handled correctly. Management needs to find a common ground to operate under and show respect for its team members. It is, therefore, important that the right communication tool is being used when communicating to reduce miscommunication or any loss of information. It is so easy to misinterpret a message by any party involved, causing delays or frustrations in the process. Of course, good working chemistry, respect, and a willingness to help can compensate for many of the challenges that a team may face.

\section{Communication}

If you rarely meet your team members, such a scenario can lead to focusing more on the task and ignoring the team-which can lead to less engagement and reduced performance in the long run (Graber, 2015). One needs to find a balance to succeed. In addition, English might not be everyone's first language, which can cause communication challenges along with time zone issues. For example, Volvo has taken the issue regarding effective communication and serious motivation for its virtual workers to make the teams as effective as possible. Volvo has established manufacturing in 19 countries, providing sales in 180 countries and employing 120,000 workers. Therefore, Volvo must seek to support team effectiveness around the globe to reach its business objectives (Adamson, 2009). Volvo is found to evaluate the effectiveness of its virtual teams with various metrics in four major categories that can be framed in the form of the following four questions: a) how aligned is the team's understanding of goals, actions, and expected results; b) how familiar is the team with roles and responsibilities; c) how comfortable is the team with communicating internally; and d) how clear are project timelines and milestones (Adamson, 2009; Nelson \& Quick, 2013).

\section{Trust and Structure}

There also needs to be a high trust culture in which teamwork and collaboration is the norm. Without trust, at a distance it becomes almost impossible for the team to succeed because its members lack familiarity with one another; such is less of an issue when they work in the same location. Therefore, there must be ample collaboration tools 
and resources available for all team members to communicate. It is important that the organization has the resources to buy and support state-of-the-art technologies for the teams to become successful and for the organization to remain competitive. This will make the team interaction to feel more like a face-to-face experience. It also gives a better outward impression. As Graber (2015) pointed out, focusing too much on technology and too little on the process will not give the organization the result it would like. Industry or organizational standards and procedures should be in place to better coordinate efforts and lead to a more standardized, consistent, and higher quality work process. This is, of course, important in any team structure-remote or not. Further, each project should have clearly written goals, objectives, project specifications, and performance metrics for the team to follow to avoid confusion, which can delay a project quite a bit. Since employees may be working in multiple locations, it will also be beneficial for the organization to create a knowledge base system where employees can look up prior notes, documents and projects as it is easy to become isolated and not know what is going on in the department. The organization can also benefit from its human resources office having policies, reward or recognition systems, or career development plans in place to address the unique need of virtual team members.

\section{OBJECTIVES AND METHODOLOGY}

A quantitative survey was distributed to target graduate students who were enrolled in graduate courses and participating in project-based learning opportunities. The survey consists of 11 questions and includes demographic items, such as major, courses in which the participants are enrolled, gender, age, location of origin and team size. The focus of this study is to look at the student perception of collaborative work at a distance, as well as the factors that impact their success and challenges with the team environment and the tools used to collaborate. This study attempts to find out how well-prepared information systems graduate students are for the digital workforce. This is now more important than ever because employees are starting to work more frequently from home. The survey questions were developed based on prior semester experiences dealing with collaboration success, team challenges, perception of e-collaboration and tools used.

This study aims to answer the following two research questions:

1. What are the factors that influence the students' overall team collaboration environment?

Questions 7, 8, 10 and 11 in the survey were used to address the first research question. The students were asked to identify the type of collaboration tools they used for their project by checking all that apply. Furthermore, the students were asked to expand upon their preferences by rating their collaboration experience and identifying their satisfaction level with the tools used, benefits and challenges that the team members may have faced during the process. 
2. Does the usage of e-collaboration tools influence project success?

Question 9 in the survey was used to address the second research question where students were asked to identify challenges that the team members may have faced during the project process.

\section{FINDINGS}

A total of 258 questionnaires were completed by students enrolling in the information systems program. In total, $90.7 \%$ of the participants were information systems majors and $9.3 \%$ were MBA students with a concentration in information systems. Further, the data showed there were $79.1 \%$ male and $20.9 \%$ female participants in these projects; this ratio is quite normal for an IT major.

The participants ranged in age from 23 to 58 and their age was used to determine the generation to which they belonged, as defined below. Table 1 lists the number and percentage of students in each generation. The majority of participants were Generation Y, but Generation X and Baby Boomers were also represented. Since these students were enrolled in graduate courses, there were no Generation $\mathrm{Z}$ participants present at this time.

Table 1. Participants by generation

\begin{tabular}{|l|l|l|l|l|}
\hline \multicolumn{1}{|c|}{ Generation } & \multicolumn{1}{c|}{ Year of Birth } & \multicolumn{1}{c|}{ N=258 } & \multicolumn{1}{c|}{ Age } & \multicolumn{1}{c|}{$\%$} \\
\hline Gen Y & $1981-1994$ & 168 & $34-21$ & 65.1 \\
\hline Gen X and BB combined & & 90 & $35-70$ & 34.9 \\
\hline Gen X & $1961-1980$ & 84 & $54-35$ & 32.6 \\
\hline Baby Boomer (BB) & $1945-1960$ & 6 & $70-55$ & 2.3 \\
\hline
\end{tabular}

Figure 1 lists the participants' location of origin, consisting of the United States (48.8\%), Middle East (19.8\%), Asia (16.3\%), Europe (10.5\%), and South America $(4.7 \%)$. Nevertheless, with such small sample sizes in several of the categories, one opted not to try to make inferences pertaining to the location of origin in this study.

The participants were further divided into project teams for the entire semester and the groups ranged in size from 3, 4, 5, 26 to 30 students. For the larger teams, the participants were further divided into subgroups to reflect a realistic software development work situation. Some of the students were dedicated to the backend process, some to the frontend development process and documentation etc. The student teams were tried balanced based on skills and knowledge level.

Figure 2 depicts the technologies that the participants preferred to use during their team project. The participants reported that their top preferred technologies to communicate between team members were e-mail (97.7\%); Google Docs (77.9\%); cloud storage, such as Dropbox (58.1\%); social media sites, such as Facebook (46.5\%); 
Figure 1. Location of origin

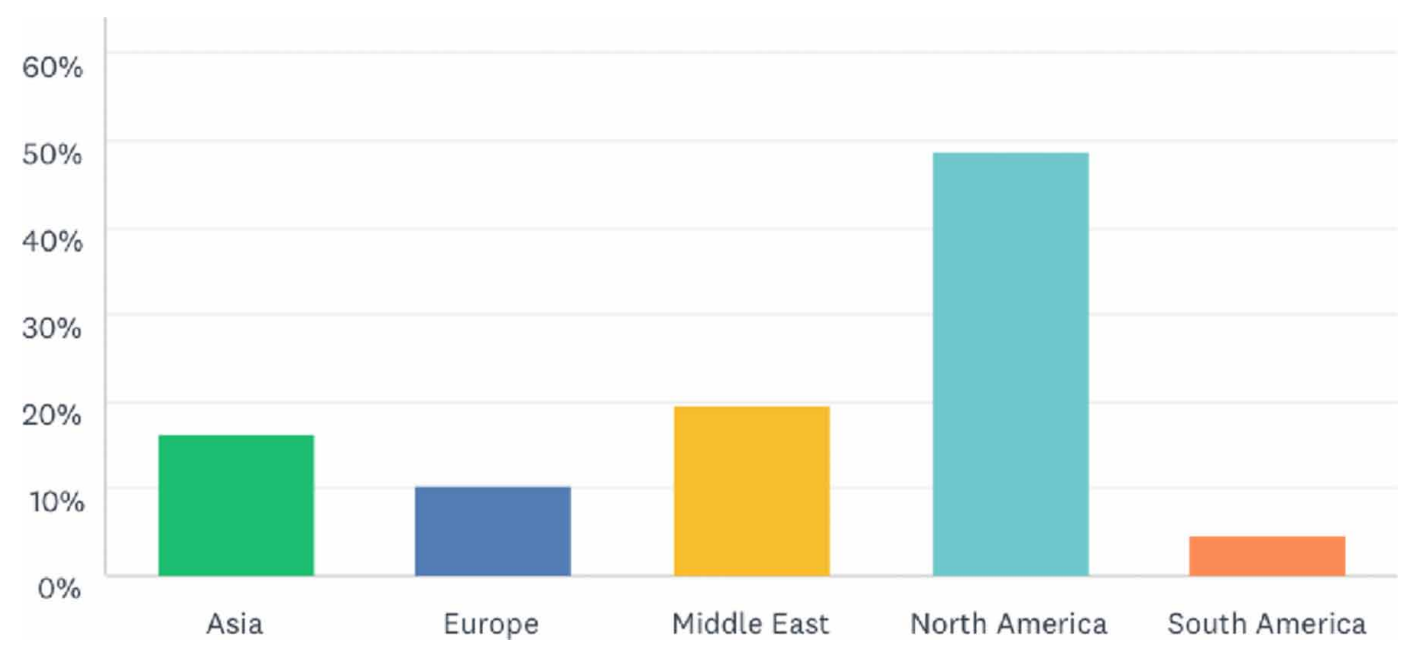

Figure 2. Tools used to collaborate

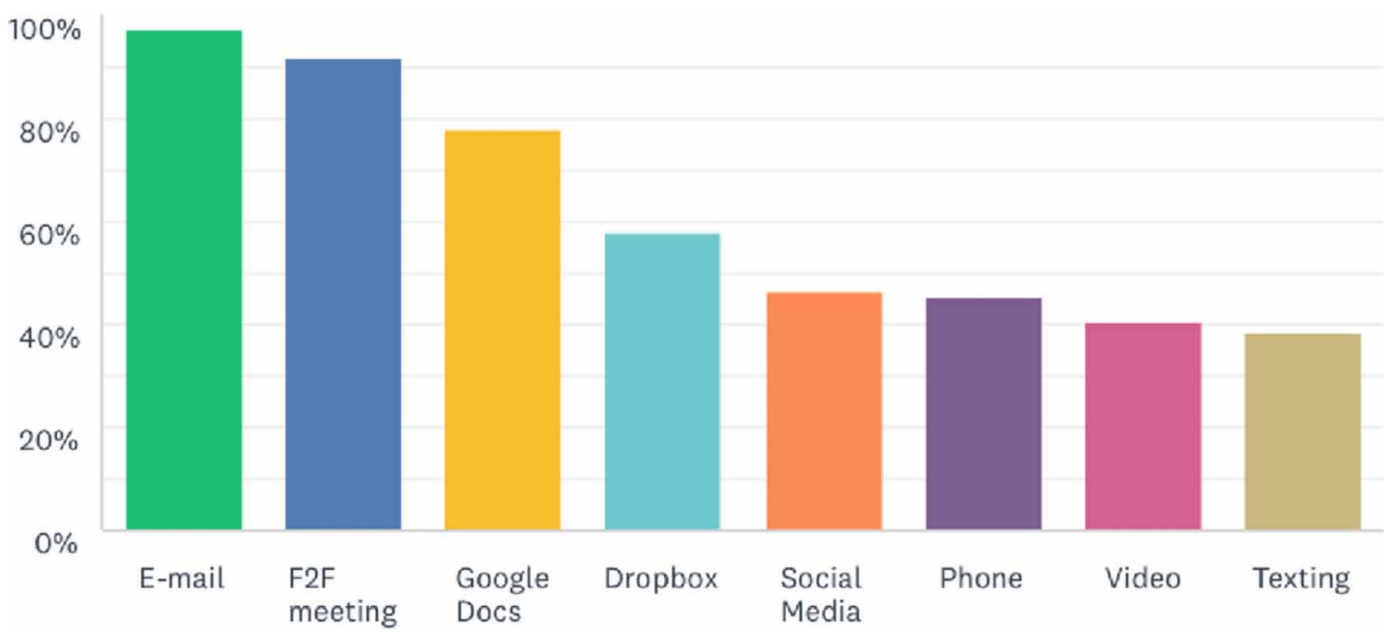

telephone (45.3\%); video, such as Skype, Zoom, or FaceTime (40.7\%); and instant messaging (38.4\%). However, interestingly enough, $91.9 \%$ of the respondents still wanted to collaborate on their project through face-to-face meetings and use the tools as a supplement to their traditional meetings to coordinate between and during gatherings. This may cause problems in the future if the pandemic prolongs and the higher education sector is forced to change their way of teaching.

In Table 2, the students were asked to rate their experience on a scale from 1 to 5 , where 5 is the highest (strongly agree) and 1 is lowest (strongly disagree). In the question that pertains to equal contributions among team members, there is a significant difference $(p .004<.05)$. Male students with a mean of $3.99(\mathrm{SE}=.07)$ 
Table 2. Please rate the following statements: Collaboration success

\begin{tabular}{|l|l|l|l|l|l|c|}
\hline & Gender & \multicolumn{1}{|c|}{$\mathbf{N}$} & \multicolumn{1}{|c|}{ Mean } & \multicolumn{1}{|c|}{ S.D. } & S.E. mean & P-value \\
\hline \multirow{2}{*}{ Enjoy collaboration with peers } & Female & 54 & 4.2778 & .94003 & .12792 & .081 \\
\cline { 2 - 8 } & Male & 204 & 4.5147 & .55689 & .03899 & \\
\hline \multirow{2}{*}{$\begin{array}{l}\text { Collaboration effect on learning and } \\
\text { inspiration }\end{array}$} & Female & 54 & 4.2778 & .99843 & .13587 & .336 \\
\cline { 2 - 8 } & Male & 204 & 4.3971 & .75213 & .05266 & \\
\hline \multirow{2}{*}{$\begin{array}{l}\text { Equal contribution of team members } \\
\text { Evaluation on end result of collaboration }\end{array}$} & Female & 54 & 3.5000 & 1.39744 & .19017 & .004 \\
\cline { 2 - 8 } & Male & 204 & 3.9853 & 1.00970 & .07069 & \\
\cline { 2 - 8 } & Male & 204 & 4.2059 & .88600 & .06203 & .153 \\
\hline \multirow{2}{*}{$\begin{array}{l}\text { Evaluation of overall satisfaction with } \\
\text { collaboration }\end{array}$} & Female & 54 & 4.1111 & 1.00314 & .13651 & .119 \\
\cline { 2 - 8 } & Male & 204 & 4.3088 & .77378 & .05418 & \\
\hline
\end{tabular}

were found to be more satisfied than the women with a mean of 3.50 ( $\mathrm{SE}=.19$ ) with the team contribution. However, the results clearly indicated a positive experience for both groups. For the other four questions, there were no significant differences for either gender or age group.

Some of the challenges that the team members may have experienced during their semester-long work process are displayed in Table 3. Comparing the following factors to gender, there is a statistically significant difference in lack of coordination (p .012<.05) with a mean of 2.76 (SE .08) for males and 2.33 (SE .14) for females. Likewise, the level of conflict shows a significant difference $(\mathrm{p} .028<.05)$ with a mean of 2.47 (SE .08) for males and 2.11 (SE .14) for females. In both cases, the male students indicated a greater challenge handling the coordination process; they

Table 3. Please rate the following statements: Collaboration challenges

\begin{tabular}{|l|l|l|l|l|l|l|}
\hline & Gender & \multicolumn{1}{|c|}{$\mathbf{N}$} & \multicolumn{1}{|c|}{ Mean } & \multicolumn{1}{|c|}{ S.D. } & S.E. mean & P-value \\
\hline \multirow{3}{*}{ Social loafing } & Female & 54 & 3.0000 & 1.46661 & .19958 & .341 \\
\cline { 2 - 8 } & Male & 204 & 3.2059 & 1.13466 & .07944 & \\
\hline \multirow{3}{*}{ Lack of coordination } & Female & 54 & 2.3333 & 1.06399 & .14479 & .012 \\
\hline & Male & 204 & 2.7647 & 1.12890 & .07904 & \\
\hline \multirow{3}{*}{$\begin{array}{l}\text { Conflict } \\
\text { Lack trust }\end{array}$} & Female & 54 & 2.1111 & .94503 & .12860 & .061 \\
\cline { 2 - 8 } & Male & 204 & 2.4265 & 1.13150 & .07922 & \\
\hline \multirow{2}{*}{$\begin{array}{l}\text { Different work backgrounds among team } \\
\text { members }\end{array}$} & Female & 54 & 2.1111 & 1.00314 & .13651 & .028 \\
\hline & Male & 204 & 2.4706 & 1.08010 & .07562 & \\
\hline \multirow{2}{*}{\begin{tabular}{l} 
Cultural differences in the team \\
\cline { 2 - 8 }
\end{tabular}} & Male & 204 & 3.2647 & 1.04033 & .07284 & .437 \\
\hline
\end{tabular}


also stated that team conflicts can be an issue. We all know that coordinating tasks can be a challenging process and that it is part of the students learning experience. When comparing the age groups, there is a significant difference when it comes to the issue of social loafing ( $.027<.05$ ), where Generation $X$ and Baby Boomers were combined with a mean of 3.37 (SE .10), which indicated this to be a bigger issue than for Generation $\mathrm{Y}$ at 3.05 (SE .10). This might have something to do with Generation $\mathrm{Y}$ being more mature and most of them working full time while going to school. Many of the students also had several years of work experience, which makes them more advanced. Comparing the genders and viewing the collaboration challenges to the Likert-scale this was not really a big issue for any of the students. They handled the team situation quite well and rated their satisfaction with collaboration similarly.

Table 4 displays the participants' feelings for their e-collaboration experience. In terms of the question whether or not e-collaboration tools help to keep everyone on the team in the loop, there is a significant difference $(\mathrm{p} .008<.05)$ in which the female students, with a mean of 4.56 (SE .07), felt that the tools were of better help than the male students at 4.31 (SE .04). In terms of difficulty of use, there is also a significant difference $(\mathrm{p} .022<.05)$ in which the students disagreed with the statement and the male students, at 2.47 (SE .07), found it a little less challenging than the female students, with a mean of 2.11 (SE .14). For the statement regarding the level of fun, there were also a significant difference between the gender $(p .002<.05)$ in

Table 4. Please rate the following statements: Perception of e-collaboration

\begin{tabular}{|c|c|c|c|c|c|c|}
\hline & Gender & $\mathbf{N}$ & Mean & S.D. & S.E. mean & P-value \\
\hline \multirow{2}{*}{$\begin{array}{l}\text { Use of e-collaboration tools helps } \\
\text { to keep everyone on the team in the } \\
\text { loop }\end{array}$} & Female & 54 & 4.5556 & .50157 & .06826 & .008 \\
\hline & Male & 204 & 4.3088 & .62597 & .04383 & \\
\hline \multirow[t]{2}{*}{ Help to advance project ideas } & Female & 54 & 4.3333 & .82416 & .11215 & .504 \\
\hline & Male & 204 & 4.2500 & .75674 & .05298 & \\
\hline \multirow[t]{2}{*}{ Helps to deliver the project faster } & Female & 54 & 4.3333 & .82416 & .11215 & .930 \\
\hline & Male & 204 & 4.3235 & .69710 & .04881 & \\
\hline \multirow[t]{2}{*}{ Makes it easier to collaborate } & Female & 54 & 4.4444 & .83929 & .11421 & .373 \\
\hline & Male & 204 & 4.3382 & .76132 & .05330 & \\
\hline \multirow[t]{2}{*}{ Difficult to use } & Female & 54 & 2.1111 & 1.00314 & .13651 & .022 \\
\hline & Male & 204 & 2.4706 & 1.02391 & .07169 & \\
\hline \multirow[t]{2}{*}{ Not fun } & Female & 54 & 1.9444 & .71154 & .09683 & .002 \\
\hline & Male & 204 & 2.3235 & 1.00894 & .07064 & \\
\hline \multirow[t]{2}{*}{ No benefits } & Female & 54 & 1.8889 & .66351 & .09029 & .717 \\
\hline & Male & 204 & 1.9412 & 1.00072 & .07006 & \\
\hline \multirow[t]{2}{*}{ Prefer in-person interaction } & Female & 54 & 2.6111 & 1.12295 & .15281 & .000 \\
\hline & Male & 204 & 3.4412 & 1.00808 & .07058 & \\
\hline
\end{tabular}


which the students disagreed with the statement. However, the female students, at 1.94 (SE .10), found the teamwork less enjoyable than the male students at 2.32 (SE .07). This For the last statement, which involves preferences for personal interaction ( $\mathrm{p} .000<.05)$, there is also a significant difference where the male students, with a mean of 3.44 (SE .07), showed a higher preference for face-to-face interaction than their female counterparts, at 2.61 (SE .15). The test shows there were no significant differences between the age groups.

Overall, the participants were pleased using various collaboration tools during their project in an attempt to communicate and share files. In terms of a significant difference in opinion (p .000<.05) regarding video (e.g., Skype, Zoom or FaceTime), female students rated video conferencing tools at 4.44 (SE .12) compared to 3.93 (SE .06) for male students. Female students were more pleased than their male counterparts with collaborating by using video conferencing tools when working on a software engineering or business analytics project. The same is true when comparing age groups ( $\mathrm{p} .046<.05)$. Students in Generation X and Baby Boomers where more pleased with video conferencing at 3.97 (SE .08) than Generation Y at 3.75 (SE .07).

\section{DISCUSSION}

While leaders in the public and private sectors were quick to point out the myriad of benefits of virtual teams (e.g., lower costs, higher productivity, access to the global talent pool, and greater flexibility for employees), global leaders have struggled to effectively manage remote teams. No organization or higher institution was ready for what just happened during the pandemic outbreak. It was a steep learning curve for all. A process like this is even challenging for students without a pandemic. However, it is very easy for the communication process to become cold, as there

Table 5. Collaboration tools used

\begin{tabular}{|l|l|l|l|l|l|c|}
\hline & \multicolumn{1}{|c|}{ Gender } & \multicolumn{1}{|c|}{$\mathbf{N}$} & \multicolumn{1}{c|}{ Mean } & \multicolumn{1}{c|}{ S.D. } & \multicolumn{1}{c|}{ S.E. mean } & P-value \\
\hline \multirow{3}{*}{ Google Docs } & Female & 54 & 4.2222 & .71814 & .09773 & .989 \\
\cline { 2 - 7 } & Male & 204 & 4.2206 & .76588 & .05362 & \\
\hline \multirow{3}{*}{ E-mail } & Female & 54 & 4.2222 & .98415 & .13393 & .414 \\
\cline { 2 - 8 } & Male & 204 & 4.3382 & .63425 & .04441 & \\
\hline \multirow{3}{*}{ Cloud Storage } & Female & 54 & 4.4444 & .90422 & .12305 & .000 \\
\cline { 2 - 8 } & Male & 204 & 3.9265 & .81215 & .05686 & \\
\hline \multirow{3}{*}{ Instance Messaging } & Female & 54 & 4.2222 & .79305 & .10792 & .473 \\
\cline { 2 - 8 } & Male & 204 & 4.1324 & .82279 & .05761 & \\
\hline \multirow{2}{*}{ Social Media Sites } & Female & 54 & 3.8889 & .81650 & .11111 & .962 \\
\cline { 2 - 8 } & Male & 204 & 3.8824 & .91828 & .06429 & \\
\hline
\end{tabular}


is no real face-to-face relationship over the table or down the hallway. Employees can easily become less motivated when sitting by themselves for hours in front of a computer and misunderstandings can easily take place when there are no facial clues. It is, therefore, important to use appropriate collaboration tools to reduce the distance. It is also important that organizations try to minimize the number of office meetings, as this can be hard on workers if they live in different time zones and work different hours.

Every country and business are faced with an increase in globalization and now with the pandemic we all are facing; the ability to collaborate at a distance has become an important skill to acquire. Academia must prepare its graduates for tomorrow's workforce and ensure that students are ready by incorporating project-based learning into its curricula. Students must learn to collaborate effectively from a distance by using various electronic tools. Many youngsters are quite social (like to be around people); therefore, social distancing can easily become a challenge. Social distancing does not mean a student is socially isolated but rather that the student must communicated digitally. Students like to meet up at Starbucks or at the mall to study and do homework. The pandemic is changing college life ranging from athletics, dormitory too dining halls. If colleges are planning to have its students return to campus, the universities must really get new routines in place regarding cleaning the dormitories and other university facilities as it stands now.

Now everything is supposed to be conducted from home in isolation. For this educational preparation to be successful, businesses and governments need to form close partnerships with universities to train students for tomorrow (Linnes, 2016) and universities must really ensure they have the proper tools in place and get its faculty ready to handle a new teaching situation to continue to attract students and keep them motivated and ensure they graduate on time. Previous studies have warned that student performance, particularly for students who are already academically struggling, can seriously suffer in online courses. There are still faculty who use transparencies or write on the board. It is therefore important for universities to train its faculty, so they feel comfortable turning their instructions online (Xu \& Jaggars, 2013). Furthermore, students must have equitable access to the Internet. Governments might need to subsidize Internet access at home for those families who cannot afford paying for the Internet. There might also be economic hardship where some student might not be able to afford going back to college.

We will also most likely see changes in the enrollment management process allowing for year-round recruitment, new financial models, vision planning, where the focus will be on collaborating and not just competing (Dennis, 2020). Those universities who have focused on online education has certainly an advantage, one school that comes to mind is Southern New Hampshire University. They are so professional in the way they handle their online material and will not feel the pandemic affecting their teaching as much as some universities conducting all face-to-face. They are 
ahead of the curve. Many universities can face a decline in enrollment as students can potentially change their plan of where they are willing to go to college. The old forecasting model universities are using to predict first year student enrollment will not work anymore. There will be other factors that will come into play in student and parent decision making. As mentioned earlier, international students might now be able to enter the country as freely as before. Universities relying on foreign students might have to consider offering need-based and merit-based scholarships to attract students. Even though a university might require students to get COVID-19 tested to be able to have the students return to campus, the administration has no control over where a student travels after enrollment. Universities are looking at everything from fully remote, HyFlex, on campus, starting and finishing up early.

The COVID-19 has also provided the universities new opportunities as forcing everyone to take part in the digital transformation. Remember "all that universities have changed over the years is the color of the chair the students are sitting on", the instruction has remained pretty much the same. At a record speed the entire higher education sector has been able to transform its way of teaching. This is quite amazing and exciting. If students are not pleased with the online instruction they are receiving, they might go to another university that has better tools and who has trained its faculty to handle the change. We could potentially see the university landscape change. According to Deloitte (2020) some universities have already asked their state attorney if they could borrow money from their endowment interest free and promise to pay back. Another suggestion is for universities to ask their donors to turn their gifts to unrestricted gifts to help with the current economic crises the pandemic has caused. We might see new academic programs evolve from this pandemic.

\section{CONCLUSION}

Project-based learning gives students an excellent opportunity to work with classmates from different countries. The background of the students can also vary quite a bit, which gives them an advantage later in life as they have learned to work with team members from different cultural upbringings and across language barriers and skill level. These factors among social loafing are, of course, the factors that influence the students' overall success level while working on a project.

The organizational digital toolbox exists and includes technologies that employees need to perform their job virtually. This toolbox will, of course, vary from organization to organization. In this study, the participants had access to e-mail, Google Docs, cloud storage, social media tools, instant messaging, video tools, chat, telephone and, of course, various development tools, a course site (blackboard), dedicated project servers and a virtual desktop with various software for the entire team to access. From this study one can clearly see that all the participants valued their projectbased learning experience, regardless of age or gender. Students were found to be comfortable collaborating and sharing files online, but the majority of the students 
still preferred to have face-to-face meetings during the development process as it is difficult to develop trust and communicate from a distance. We all are social creatures. Therefore, it is very important for organizational leaders to communicate effectively and understand that people are different and have varying work styles. Technologies can help the process, but without proper communication skills from the leadership and among the team members the task will go less efficient, and the satisfaction level will drop. Universities have some work to do.

At the end of the term, the projects were successful, the clients were pleased with the outcome, and students learned to overcome the difficulties of using technologies to collaborate and communicate. The team goal helped the teams to focus and move forward with their tasks. The industry projects were extremely popular among the students as they gain real life experience and learn to adjust to the customer's needs. 


\section{REFERENCES}

Adamson, V. (2009). Volvo - Driving Virtual Team Productivity. In Enterprise 2.0 Conference, Boston, MA.

Ang, S., \& Van Dyne, L. (2008). Handbook of Cultural Intelligence: Theory, Measurement, and Applications. Taylor \& Francis.

Ballenstedt, B. (2014). Telework Yields \$32 Million in Snow Day Savings. Retrieved from https://www.nextgov.com/cio-briefing/wired-workplace/2014/03/teleworkyields-32-million-snow-day-savings/79750/

N. Baloian, F. Burstein, H. Ogata, F. Santoro, \& G. Zurita (Eds.). (2014). Collaboration and Technology: 20th International Conference, CRIWG 2014, Santiago, Chile, September 7-10, 2014, Proceedings (Vol. 8658). Springer.

Brandt, V., England, W., \& Ward, S. (2011). Virtual teams. Research Technology Management, 54(6), 62-63.

Browne, R. (2018). 70\% of people globally work remotely at least once a week, study says. Retrieved from: https://www.cnbc.com/2018/05/30/70-percent-of-peopleglobally-work-remotely-at-least-once-a-week-iwg-study.html

Bureau of Labor Statistics. (2016). American Time Use Survey Summary. Retrieved from https://www.bls.gov/news.release/atus.nr0.htm

CBC News. (2013). Yahoo bans working from home. Retrieved from http://www.cbc. ca/ news/business/yahoo-bans-working-from-home-1.1300497

Chen, C. C., Wu, J., Yang, S. C., \& Tsou, H.-Y. (2008). Importance of Diversified Leadership Roles in Improving Team Effectiveness in a Virtual Collaboration Learning Environment. Journal of Educational Technology \& Society, 11(1), 304-321.

Ciotti, G. (2016). How Remote Teams Are Becoming the Future of Work. Retrieved from https://www.helpscout.net/blog/virtual-teams/

CISCO. (2009). Cisco Study Finds Telecommuting Significantly Increases Employee Productivity, Work-Life Flexibility and Job Satisfaction. Retrieved from https:// newsroom.cisco.com/press-release-content?articleId $=5000107$

Deloitte. (2020). COVID-19's impact on higher education: Strategies for tackling the financial challenges facing colleges and universities. Retrieved from: https://www2. deloitte.com/ content/dam/Deloitte/us/Documents/public-sector/us-gps-covid-19impact-on-higher-education.pdf

Deloitte. (n.d.). The digital workplace: think, share, do transform your employee experience. Retrieved from: https://www2.deloitte.com/content/dam/Deloitte/mx/ Documents/human-capital/The_digital_workplace.pdf 
Dennis, M. (2020). Higher education opportunities after COVID-19. Retrieved from: https://www.university worldnews.com/post.php?story=20200507152524762

DePass, D. (2016). Honeywell ends telecommuting options. Retrieved from https:// www.startribune.com/honeywell-ends-telecommuting-option/397929641/

Dixon, M. (2019). The IWG Global Workspace Survey. Retrieved from: https://assets. regus.com/pdfs/iwg-workplace-survey/iwg-workplace-survey-2019.pdf

Economist Intelligence Unit. (2009). Managing Virtual Teams: Taking a More Strategic Approach. Retrieved from http://graphics.eiu.com/upload/eb/NEC_Managing_virtual_ teams_WEB.pdf

Ferrazzi, K. (2012). Virtual Teams Can Outperform Traditional Teams. Retrieved from https://hbr.org/2012/03/how-virtual-teams-can-outperfo

Global Workplace Analytics. (2015a). Costs and Benefits. Retrieved from https:// globalworkplaceanalytics.com/resources/costs-benefits

Global Workplace Analytics. (2015b). Latest Telecommuting Statistics. Retrieved from https://globalworkplaceanalytics.com/telecommuting-statistics

Global Workplace Analytics. (2020). Work-At-Home After Covid-19-Our Forecast. Retrieved from: https://globalworkplaceanalytics.com/work-at-home-after-covid-19our-forecast

Graber, S. (2015). Why Remote Work Thrives in Some Companies and Fails in Others. Retrieved from https://hbr.org/2015/03/why-remote-work-thrives-in-some-companiesand-fails-in-others

Graham, C. M., Daniel, H., \& Doore, B. (2020). Millennial Teamwork and Technical Proficiency's Impact on Virtual Team Effectiveness: Implications for Business Educators and Leaders. In Five Generations and Only One Workforce: How Successful Businesses Are Managing a Multigenerational Workforce (pp. 283-303). IGI Global. http://doi:10.4018/978-1-7998-0437-6.ch013

Graham, M. C., \& Miaoulis, G. (2013). The Case for a SMS Texting Integrated Classroom: Learning Preferences and Student Perceptions. Journal of Innovative Education Strategies, 2(1), 51-58.

Hamburg, I. (2019). Implementation of a Digital Workplace Strategy to Drive behavior Change and Improve Competencies. Retrieved from https://www.intechopen.com/ books/strategy-and-behaviors-in-the-digital-economy/implementation-of-a-digitalworkplace-strategy-to-drive-behavior-change-and-improve-competencies

Heller, R., Laurito, A., Johnson, K., Martin, M., Fitzpatrick, R., \& Sundin, K. (2010). Global Teams: Trends, Challenges and Solutions. Retrieved from https://est05. esalestrack.com/eSalesTrack/Content/Content.ashx?file=4578f59e-21b3-4a2c-bbfe63e53af3f5dc.pdf 
Inavero Inc. (2018). 2018 Future Workforce Report: Hiring manager insights on flexible and remote work trends. Retrieved from https://www.slideshare.net/upwork/2018future-workforce-report-hiring-manager-insights-on-flexible-and-remote-worktrends/1

Internet World Stats. (2020). Internet Users and 2019 Population in North America. Retrieved from: https://www.internetworldstats.com/stats 14.htm

Johnson, J. P., Lenartowicz, T., \& Apud, S. (2006). Cross-cultural competence in international business: Toward a definition and a model. Journal of International Business Studies, 37(4), 525-543. doi:10.1057/palgrave.jibs.8400205

Jones, J. F. (2015). In U.S., Telecommuting for Work Climbs to 37\%. Retrieved from https://www.gallup.com/poll/184649/telecommuting-work-climbs.aspx

Karna, D., \& Ko, I. (2013). Collaboration orientation, peer support and the mediating effect of use of e-collaboration on research performance and satisfaction. Asia Pacific Journal of Information Systems, 23(4), 151-175. doi:10.14329/apjis.2013.23.4.151

Kayworth, T., \& Leidner, D. (2000). The global virtual manager: A prescription for success. European Management Journal, 18(2), 183-194. doi:10.1016/S02632373(99)00090-0

Knock, N. (2008). A Basic Definition of E-Collaboration and its Underlying Concepts. In N. Kock (Ed.), Encyclopedia of E-Collaboration (pp. 48-53). IGI Global. doi:10.4018/978-1-59904-000-4.ch008

Knuppel, B. (2015). Virtual Teams Are Growing Faster Than Managers Can Learn to Lead Them. Retrieved from http://www.ceo.com/operations/virtual-teams-are-growingfaster-than-managers-can-learn-to-lead-them/

Kock, N., \& D’Arcy, J. (2002). Resolving the e-collaboration paradox: The competing influences of media naturalness and compensatory adaption. Information Management and Consulting, 17(4), 72-78.

Kock, N., Davidson, R., Ocker, R., \& Wazlawick, R. (2001). E-collaboration: A look at past research and future challenges. Journal of Systems and Information Technology, 5(1), 1-9. doi:10.1108/13287260180001059

Kratz, G. (2016). The Business Case: How Work Flexibility Can Help Companies Save Money. Retrieved from https://www.workflexibility.org/business-case-workflexibility-can-help-companies-save-money/

Linnes, C. (2016). E-Tools for E-Team: The Importance of Social Ties and Knowledge Sharing. In C. Graham (Ed.), Strategic Management and Leadership for Systems Development in Virtual Spaces (pp. 90-109). IGI Global. doi:10.4018/978-1-46669688-4.ch006 
Lipnack, J., \& Stamps, J. (1997). Virtual teams: reaching across space, time, and organizations with technology. Wiley.

Marks, M. A., Sabella, M. J., Burke, C. S., \& Zacaro, S. J. (2002). The Impact of Cross-Training on Team Effectiveness. The Journal of Applied Psychology, 87(1), 3-13. doi:10.1037/0021-9010.87.1.3 PMID:11916213

Marowits, R. (2016). Telecommuting growing as companies look to save money, respond to employees. Retrieved from https://www.cbc.ca/news/business/telecommutinggrowing-as-companies-look-to-save-money-respond-to-employees-1.3596420

Martins, L. L., Gilson, L. L., \& Maynard, M. T. (2004). Virtual teams: What do we know and where do we go from here? Journal of Management, 30(6), 805-835. doi:10.1016/j.jm.2004.05.002

Morrison-Smith, S., \& Ruiz, J. (2020). Challenges and barriers in virtual teas: a literature review. Retrieve from https://link.springer.com/article/10.1007/s42452020-2801-5

Mosca, L. (2017). Working From Home: Don't Allow it! Retrieved from https:// www.forbes.com/sites/louismosca/2017/06/29/working-from-home-dont-allowit/\#1f190cb6f9c7

Nelson, D. L., \& Quick, J. C. (2013). Organizational Behavior: Science, the Real World, and You (8th ed.). Cengage Learning.

Oertig, M., Buergi, T. (2006). The challenges of managing cross-cultural virtual project teams. Team Performance Management, 12(1/2), 23-30. doi:065277410.1108/1352759061

Parris, J. (2013). Some Employees Afraid to Work Remotely, According to new Study. Retrieved from https://www.flexjobs.com/blog/post/some-employees-afraid-to-workremotely-according-to-new-study/

PWC. (2013). Millennial Workers Want Greater Flexibility, Work/Life Balance, Global Opportunities. Retrieved from http://press.pwc.com/News-releases/NextGen-globalgenerational-study/s/376ce2a9-1769-46f2-a228-8b97d252f660

Radu, S. (2018). How Soon Will You Be Working From Home? Retrieved from https://www.usnews.com/news/best-countries/articles/2018-02-16/telecommutingis-growing-but-still-not-unanimously-embraced

Razmerita, L., \& Kirchner, K. (2019). What factors impact successful collaboration in virtual learning environments? A study of Massive Open Online Course (MOOCs). In Research in Management Learning and Education (pp. 38-39). RMLE. 
Razmertita, L., \& Kirchner, K. (2015). Collaboration and E-collaboration: A Study of Factors that Influence Perceived Students' Group Performance. $201548^{\text {th }}$ Hawaii International Conference, 33-42. Retrieved from https://www.researchgate.net/ publication/271076365_Collaboration_and_E_Collaboration_A_Study_of_Factors_ that_Influence_Perceived_Students\%27_Group_Performance

Reynolds, B. (2014, October 1). Survey: People Who Want Flexible Jobs and Why. Retrieved from https://www.flexjobs.com/blog/post/survey-people-who-want-flexiblejobs-and-why/

Reynolds, B. (2018). 100 Top Companies with Remote Jobs in 1018. Retrieved from https://www.flexjobs.com/blog/post/100-top-companies-with-remote-jobs-in-2018/

Roberts, D. (2014). Bank of America tells more workers to come into the office. Retrieved from https://www.charlotteobserver.com/news/business/banking/article9200630.html

Schwartz, A. (2009). Cisco Says Telecommuting Saves Money, and the World. Retrieved from https://www.fastcompany.com/1300971/cisco-says-telecommuting-saves-moneyand-world

Shapiro, J. M., Ozanne, J. L., \& Saatcioglu, B. (2008). An interpretive examination of the development of cultural sensitivity in international business. Journal of International Business Studies, 39(1), 71-87. doi:10.1057/palgrave.jibs.8400327

SHRM. (2019). 2019 Challenges and Benefits of Global Teams - An HR Perspective. Retrieved from https://www.shrm.org/hr-today/trends-and-forecasting/research-andsurveys/Docum ents/SHRM\%20Globalization\%20Partners\%20Global\%20Teams\%20 Report.pdf

SHRM. (2020). Understanding and Developing Organizational Culture. Retrieved from: https://www.shrm.org/resourcesandtools/tools-and-samples/toolkits/pages/ understandinganddevelopingorganizationalculture.aspx

Singletary, M. (2014). Teleworking saves money - but let's keep it honest. Retrieved from https://www. washingtonpost.com/business/teleworking-saves-money--butlets-keep-it-hon est/2014/08/14/a82035e6-23c1-11e4-958c268a320a60ce_story. html?utmterm $=$. bfdf $4081 \mathrm{f} 22 \mathrm{~d}$

Statista. (2020). Global Digital Population as of April 2020. Retrieved from: https:// www.statista.com/statistics/617136/digital-population-worldwide/

Thompson, C., \& Caputo, P. (2009). The Reality of Virtual Work: Is Your Organization Ready? Retrieved from http://www.aon.com/attachments/virtual_worker_whitepaper. pdf

Tkaczyk, C. (2013). Marissa Mayer breaks her silence on Yahoo's telecommuting policy. Retrieved from https://fortune.com/2013/04/19/marissa-mayer-breaks-hersilence-on-yahoos-telecommuting-policy/ 
Tseng, H., Ku, H. Y., Wang, C. H., \& Sun, L. (2009). Key factors in online collaboration and their relationship to teamwork satisfaction. Quarterly Review of Distance Education, 10(2).

Tugend, A. (2014). It's Unclearly Defined, but Telecommuting Is Fast on the Rise. Retrieved from https://www.nytimes.com/2014/03/08/your-money/when-working-inyour-pajamas-is-more-productive.html?_r=1

WebFinance. (2017). Electronic collaboration. Retrieved from http://www. businessdictionary. com/definition/electronic-collaboration.html

Xu, D., \& Jaggars, S. S. (2020). Adaptability to Online Learning: Differences Across Types of Students and Academic Subject Areas. The Journal of Higher Education, 85(5). Advance online publication. doi:10.1353/jhe.2014.0028

Yusuf, B. N. M. (2012). Communications and Trust Is a key Factor to Success in Virtual Teams Collaborations. International Journal of Business and Technopreneurship, 2(3), 399-413. Retrieved from: https://www.researchgate.net/publication/256422668_ Communications_and_Trust_Is_a_Key_Factor_to_Success_in_Virtual_Teams_

Collaborations

Zapier. (2020). Half of America Just Started Working From Home. So, How's it Going? Retrieved from: https://zapier.com/blog/wfh-report/

Zivick, J. (2012). Mapping global virtual team leadership actions to organizational roles. The Business Review, Cambridge, 19(2), 18-25.

Cathrine Linnes, Ph.D., is an Associate Professor at Østfold University College, Norway. Dr. Linnes has been a faculty member and program chair at Hawaii Pacific University, faculty member at Southern New Hampshire University, and faculty member at Kapiolani Community College in the United States. She is a member of the executive council of Upsilon Pi Epsilon the honor society for information and computer sciences. She holds numerous years of work experience. 